\title{
Obstetric violence and its associated factors among postnatal women in a Specialized Comprehensive Hospital, Amhara Region, Northwest Ethiopia
}

\author{
Muhabaw Shumye Mihret
}

\begin{abstract}
Objective: Obstetric violence is an often overlooked obstacle to quality maternal health care service utilization. In the study setting, there was limited evidence on obstetric violence. Hence, this study aimed at assessing the prevalence and associated factors of obstetric violence among women who gave birth in Gondar University Specialized Comprehensive Hospital, Northwest Ethiopia.

Results: A total of 409 women had been participated in the study with a response rate of $100 \%$. Three in four (75.1\%) women reported that they had been subjected to at least one form of obstetric violence during labor and delivery with $95 \% \mathrm{Cl}$ (70.9-79.0). The reported forms of obstetric violence include non-consented care-260 (63.6\%), non-dignified care-226 (55.3\%), physical abuse-192 (46.9\%), non-confidential care-132 (32.3\%, neglected care - 52 (12.7\%) and discriminated care-38 (9.3\%). On the contrary, none of the respondent had reported detention for failure to pay in the hospital. The multivariable logistic regression analysis demonstrated that urban residents $(\mathrm{AOR}=1.89 ; 95 \% \mathrm{Cl} 1.11,3.22)$ and primary school attendants ( $\mathrm{AOR}=0.49 ; 95 \% \mathrm{Cl} 0.27,0.91$ ) were significantly associated with experiencing obstetric violence. This study indicated the high prevalence of obstetric violence. Thus, interventions need to be undertaken by taking the reported forms of obstetric violence and participants' sociodemographic status in to account.
\end{abstract}

Keywords: Ethiopia, Gondar university hospital, Obstetric violence, Respectful maternity care

\section{Introduction}

Obstetric violence $(\mathrm{OV})$ is a specific type of violation of women's rights in medical practice during health care related to the child birth processes [1]. Laboring mothers may be subjected to different forms of OV during facility child birth [2]. Such ill-treatments and abuses create a psychological distance between the women and care providers and then drive women away from formal health care systems in fear of being subjected to such violence and sometimes are a more prominent hindrance than geographical or financial barriers to maternal health

\footnotetext{
*Correspondence: muhabawshumye@gmail.com

Department of Clinical Midwifery, School of Midwifery, College

of Medicine and Health Sciences, University of Gondar, Po. Box 196,

Gondar, Ethiopia
}

service utilization $[1,3-5]$. Despite this fact, OV is also an often overlooked type of obstacle to quality maternal health care service utilization as compared to other barriers $[1,6]$.

Maternal mortality (MM) remains high in many resource limited countries including Ethiopia [6-8]. To reduce such high maternal mortality (MM) and thereby to achieve target two of Sustainable Development Goal (SDG) three [9], one key identified strategy is improving access to facility delivery [10-13]. Unfortunately, only one out of four women have undergone institutional delivery in Ethiopia [4, 7]. In this perspective, an important but little understood concept that retards the universal access to facility delivery is $\mathrm{OV}[2,14,15]$. Thus, it is essential to conduct investigation on OV and its determinants. Previous studies demonstrated that $\mathrm{OV}$ had been predicted 
by factors like educational status, long stay in the hospital and residency [14-17]. However, these determinants could be varied across settings and time trend.

On top of this, there was limited evidence on OV in the study setting. Therefore; this study aimed at assessing the prevalence and associated factors of OV among immediate postnatal women in care in Gondar University Comprehensive Specialized Hospital (GUCSH), Northwest Ethiopia, 2019.

\section{Main text}

\section{Methods and materials}

An institutional based cross sectional study was conducted from April 08 to May 16/2019 in GUCSH which is located $750 \mathrm{~km}$ from the northwest of Addis Ababathe capital city of Ethiopia. The hospital is providing service for more than 7 million people of Gondar city and the catchment areas. The maternity division of the hospital is composed of antenatal care, postnatal care and three maternity wards (named as M1, M2 and M3). It is also staffed with intern doctors, Midwives, Obstetricians and supportive staffs. In 2018, a total of 9744 births were attended at the hospital. Women who gave birth at GUCSH and got discharge decision (i.e. to prevent under report of OV in their entire hospital stay) during the study period were included. Mothers who had ever experienced loss of consciousness during the hospital stay were excluded to minimize recall bias.

Sample size was initially determined for both specific objectives using Open-Epi Version 2 software (Additional file 1: Annex S1). Thereafter, the largest sample size had been taken. Thus, the current study's final sample size had been made by considering the following assumptions: ratio between women with monthly family income $<2000$ and $\geq 2000$ Ethiopian Birr-1:1, odds ratio-1.90, power $-80 \%$, confidence interval $-95 \%$, and the proportion of $\mathrm{OV}$ among exposed group- $73.5 \%$ and that of among non-exposed group-59.2\% [15]. Therefore, the largest sample size was 368 and by assuming $10 \%$ nonresponse rate, the final sample size (i.e. $368 *(1 / 1-0.10)$ ) turned to be 409.

Systematic random sampling was employed based on respondents' discharge decision order. The K-interval was made by dividing the number of cases flow in the preceding month (which was 863 ) by the sample sizes (i.e. 860/409 2). Lottery method was then used to pick the first participant among the first two women who had been earned decision for discharge. Thereafter, selection of participants had been proceeded every two interval.

The outcome variable was obstetric violence (OV) while the explanatory variables included socio-demographic and obstetric variables.
Obstetric violence (OV) was measured using the seven performance standards and their respective verification criteria developed by the Maternal and Child Health Integrated Program [18]. The seven categories of OV include physical abuse, non-consented care, non-confidential care, non-dignified care, discriminated care, neglected care and detention in the health facility. Accordingly, those women who replied 'yes' to at least one form of OV had been labeled to be subjected to OV. A total of 25 verification criteria of $\mathrm{OV}$ were used to measure the seven performance standards in the composite scale (Additional file 2: Annex S2).

Structured pretested questionnaire through face to face interview was used to collect the data. The questionnaire was designed in English and translated in to Amharic (local) language and then translated back to English to check for consistency. One day training was provided for the data collectors and supervisors. On daily basis, data were checked for completeness and accuracy and then necessary feedback was offered. All the questionnaires were checked for completeness, coded and entered in to Epi Info version 7.1.2.0 and then exported to SPSS version 20 for analysis. Descriptive statistics such as mean, percentage and standard deviation were employed. Both bivariate and multivariable logistic regression model were fitted. COR and AOR with 95\% CI were computed. Finally, statistically significant association of variables was claimed based on AOR with its 95\% CI and $\mathrm{p}$-value $\leq 0.05$.

\section{Results}

\section{Socio-demographic characteristics}

A total of 409 immediate postnatal women were interviewed making a response rate of $100 \%$. Majority $(84.8 \%)$ of the respondents' age ranged 20-34 years with mean \pm SD of $28.1 \pm 5.02$ years. About 394 (96.3\%) of mothers were married and more than half $(56.2 \%)$ of the participants were housewife by occupation. About 131 (32.03\%) of women had never attended any formal education whereas nearly one-third (34.7\%) of women had attended college and above (Table 1).

\section{Obstetric characteristics}

Majority (97.1\%) of respondents had received ANC service during their most recent pregnancy. Of them: nearly two-third (66.5\%) of the mothers received ANC by Midwives and almost two-third (65.5\%) of the participants attended complete ANC visits (Table 2).

\section{Prevalence and forms of obstetric violence}

In the study setting, the overall prevalence of OV found to be $75.1 \%$ with $95 \%$ CI (70.9-79.0). Six out of seven forms of OV had been reported by the study participants. 
Table 1 Socio-demographic characteristics of participants in Gondar University Comprehensive Specialized Hospital, Northwest Ethiopia, $2019(n=409)$

\begin{tabular}{|c|c|c|}
\hline Variables & Number & $\%$ \\
\hline \multicolumn{3}{|l|}{ Age } \\
\hline $18-19$ & 10 & 2.5 \\
\hline $20-34$ & 347 & 84.8 \\
\hline$\geq 35$ & 52 & 12.7 \\
\hline \multicolumn{3}{|l|}{ Marital status } \\
\hline Married & 396 & 96.82 \\
\hline Divorced & 7 & 1.71 \\
\hline Single & 5 & 1.22 \\
\hline Widowed & 1 & 0.25 \\
\hline \multicolumn{3}{|l|}{ Religion } \\
\hline Orthodox & 301 & 73.6 \\
\hline Muslim & 90 & 22.0 \\
\hline Protestant & 18 & 4.4 \\
\hline \multicolumn{3}{|l|}{ Ethnicity } \\
\hline Amhara & 356 & 87.0 \\
\hline Qimannt & 31 & 7.6 \\
\hline Tigray & 16 & 3.9 \\
\hline Oromo & 6 & 1.5 \\
\hline \multicolumn{3}{|l|}{ Educational attendance } \\
\hline Unable read and write & 63 & 15.4 \\
\hline Can read and write & 68 & 16.6 \\
\hline Primary school (grade 1-8) & 69 & 16.9 \\
\hline Secondary school (grade 9-12) & 67 & 16.7 \\
\hline Collage and above & 142 & 34.7 \\
\hline \multicolumn{3}{|l|}{ Occupation } \\
\hline House wife & 230 & 56.2 \\
\hline Government employee & 118 & 28.9 \\
\hline Private business & 52 & 12.7 \\
\hline Other $^{\mathrm{a}}$ & 9 & 2.2 \\
\hline \multicolumn{3}{|c|}{ Husband's educational status $(n=396)$} \\
\hline Unable read and write & 39 & 9.5 \\
\hline Can read and write & 40 & 9.8 \\
\hline Primary school (grade 1-8) & 52 & 12.7 \\
\hline Secondary school (grade 9-12) & 66 & 16.1 \\
\hline College and above & 199 & 48.7 \\
\hline \multicolumn{3}{|l|}{ Husband's occupation ( $n=396)$} \\
\hline Farmer & 61 & 15.4 \\
\hline Private business & 126 & 31.82 \\
\hline Government employee & 165 & 41.67 \\
\hline Daily laborer & 44 & 11.11 \\
\hline \multicolumn{3}{|l|}{ Families' monthly income (ETB) } \\
\hline$\leq 2500$ & 62 & 15.2 \\
\hline$>2500$ & 347 & 84.8 \\
\hline \multicolumn{3}{|l|}{ Residence } \\
\hline Urban & 282 & 68.9 \\
\hline Rural & 127 & 31.1 \\
\hline
\end{tabular}

${ }^{\mathrm{a}}$ Others $=$ student and daily laborer
Table 2 Obstetric characteristics of participants in Gondar University Comprehensive Specialized Hospital, Northwest Ethiopia, $2019(n=409)$

\begin{tabular}{|c|c|c|}
\hline Variable & Number & $\%$ \\
\hline \multicolumn{3}{|l|}{ ANC } \\
\hline Yes & 397 & 97.1 \\
\hline No & 12 & 2.9 \\
\hline \multicolumn{3}{|l|}{ Place of ANC $(n=397)$} \\
\hline Health center & 199 & 48.7 \\
\hline Hospital & 181 & 44.3 \\
\hline Private health facility & 17 & 4.2 \\
\hline \multicolumn{3}{|l|}{ ANC received from $(n=397)$} \\
\hline Doctors & 76 & 18.6 \\
\hline Midwives & 272 & 66.5 \\
\hline Inter doctors & 48 & 11.7 \\
\hline Other & 1 & 0.2 \\
\hline \multicolumn{3}{|l|}{ Number of ANC visit $(n=397)$} \\
\hline$\geq 4$ & 260 & 65.5 \\
\hline$<4$ & 137 & 34.5 \\
\hline \multicolumn{3}{|l|}{ Gravidity } \\
\hline 1 & 115 & 28.1 \\
\hline $2-3$ & 211 & 51.6 \\
\hline$\geq 4$ & 83 & 20.3 \\
\hline \multicolumn{3}{|l|}{ Parity } \\
\hline Prim parous & 128 & 31.3 \\
\hline Multi parous & 253 & 61.9 \\
\hline Grand multiparous & 28 & 6.8 \\
\hline \multicolumn{3}{|l|}{ History of previous institutional delivery } \\
\hline Yes & 219 & 53.5 \\
\hline No & 190 & 46.5 \\
\hline \multicolumn{3}{|l|}{ Number of birth attendants } \\
\hline $1-2$ & 275 & 67.2 \\
\hline $3-4$ & 116 & 28.4 \\
\hline $5-8$ & 18 & 4.4 \\
\hline \multicolumn{3}{|l|}{ Main birth attendant } \\
\hline Midwife & 193 & 47.2 \\
\hline Doctor & 157 & 38.4 \\
\hline Intern doctor & 59 & 14.4 \\
\hline \multicolumn{3}{|l|}{ Sex of main birth attendant } \\
\hline Female & 158 & 38.6 \\
\hline Male & 251 & 61.4 \\
\hline \multicolumn{3}{|l|}{ Rout/type of current delivery } \\
\hline Spontaneous vaginal delivery (SVD) & 242 & 59.2 \\
\hline Assisted vaginal delivery (AVD) & 35 & 8.6 \\
\hline Delivery by episiotomy & 77 & 18.8 \\
\hline Caesarean delivery (CD) & 55 & 13.4 \\
\hline \multicolumn{3}{|l|}{ Preferred birth position } \\
\hline Kneeling & 212 & 51.8 \\
\hline Squatting & 43 & 10.5 \\
\hline Lithotomic & 154 & 37.7 \\
\hline \multicolumn{3}{|l|}{ Labor was augmented/induced } \\
\hline Yes & 155 & 37.9 \\
\hline
\end{tabular}


Table 2 (continued)

\begin{tabular}{lcc}
\hline Variable & Number & $\%$ \\
\hline No & 254 & 62.1 \\
Transfused with blood & 19 & 4.6 \\
Yes & 390 & 95.4 \\
No & & \\
Time of delivery & 270 & 66 \\
Day & 139 & 34 \\
Night & & \\
Number of days stayed at the hospital after delivery & 328 & 80.2 \\
$\leq 3$ & 81 & 19.8 \\
$>3$ & & \\
\hline
\end{tabular}

The most common one was non-consented care-260 (63.6\%) (Additional file 3: Figure S1).

\section{Correlates of obstetric violence}

Initially, all explanatory variables had been fitted to bivariate logistic regression model. Accordingly; residence and educational status had been associated with OV. Thereafter, variables with missing values had been thrown out from the multivariable regression. In the multivariable analysis, residence and educational status had been still remained significantly correlated with OV.

Thus, urban residents were 1.89 times more likely to report $\mathrm{OV}$ as compared to rural dwellers $(\mathrm{AOR}=1.89$; $95 \%$ CI 1.11, 3.22) whereas women who had attended primary school were $51 \%$ less likely to report obstetric violence as compared to those women who had attended secondary education and above $(\mathrm{AOR}=0.49 ; 95 \% \mathrm{CI}$ $0.27,0.91$ ) (Table 3).

\section{Discussion}

This study aimed to assess obstetric violence and associated factors among women during childbirth in the study setting. The study exhibited high prevalence of OV and was significantly associated with urban resident and primary school attendant. In this study, three out of four (75.1\%) women reported to be subjected to at least one form of $\mathrm{OV}$. The prevalence of OV in the current study is consistent with that of the previous studies done in Ethiopia such as Addis Ababa-78\% [19] and Western Ethiopia-74.8\% [20].

However, the proportion of OV in this study was higher than other previous studies' report conducted in north Nigeria-55.9\% [17], Kenya-20\% [21], Brazil-18.3\% [22], Northern India-28.8\% [23] and Uttar Pradesh India-15.2\% [24]. It was also higher as compared to studies done in Ethiopia such as pooled prevalence of systematic review and meta analysis-49.4\% [25], Bahirdar city-67.1\% [15], Southern Ethiopia-21.1\% [26], four regions' observational report-36\% [27] and Northern Ethiopia-22\% [16]. This discrepancy might be due to variation in sample sizes [16, 17, 22, 26-28]. Furthermore, the disagreement could be ascribed to difference in study settings. Most of the aforementioned studies were conducted in low level settings with low clients flow unlike the current tertiary level setting with higher cases flow and abundant referral complicated cases. With overcrowded and complicated cases, care providers are likely to behave abusively. Equally, variation in the study period might contribute for such inconsistent magnitude [21, 26, $27,29]$. In addition, variation in time of interview after child birth could be another reason for the observed difference in prevalence [22].

On the contrary, the prevalence of $\mathrm{OV}$ in the present study is lower than was reported in previous study conducted in Jimma University medical center in southwest Ethiopia-91.7\% [14]. This disparity could be due to study population variation that the former study had excluded women who gave birth via caesarean section. In this perspective, the empirical evidence support that more OV had been reported among women who gave birth through vagina than caesarean section [30]. This could be due to the fact that health care providers usually tend to pay more attention for women who are indicated for caesarean delivery (for example, more likely to take informed consent strictly) than vaginal delivery thereby minimized committing obstetric OV. The current study's report also lower than that of reported in the study undertaken in Malawi-93.7\% [28]. A number of reasons could be mentioned for the observed inconsistency. One reason might be related to variation in data collection method. The data in the current study were collected through interviewing the study participants while data were collected via direct observation in the Malawi's study. Hence, the magnitude of obstetric OV when it collected through interview might be affected by participants' recalls capacity and level of perception. Another possible reason would be related to time of data collection since the previous data were collected 5 years back and thus, provider's awareness and quality of care tends to be improved across time trend. In addition, variation in sample sizes, study settings and verification criteria for the outcome variable might attribute for the observed disagreement.

The analysis in the current study revealed that women who have been living in the urban were 1.89 times more likely to report at least one form of $\mathrm{OV}$ than the rural dwellers. This finding is in line with the study done in Tigray in Northern Ethiopia [16]. It could be explained by the women's level of awareness on their rights that women who have been living in rural area are less likely to be aware. In this regard, evidence shows that women 
Table 3 Correlates of obstetric violence among mothers in care in Gondar University Comprehensive Specialized Hospital, Northwest Ethiopia, $2019(n=409)$

\begin{tabular}{|c|c|c|c|c|}
\hline \multirow[t]{2}{*}{ Variable } & \multicolumn{2}{|c|}{ Obstetric violence } & \multirow[t]{2}{*}{ COR with $95 \% \mathrm{Cl}$} & \multirow[t]{2}{*}{ AOR with $95 \% \mathrm{C}$} \\
\hline & Yes N (\%) & No N (\%) & & \\
\hline \multicolumn{5}{|l|}{ Age } \\
\hline$\leq 34$ & $264(73.9)$ & $93(26.1)$ & $0.59(0.28,1.27)$ & $0.49(0.22,1.11)$ \\
\hline$>34$ & $43(82.7 \%)$ & $9(17.3)$ & 1 & 1 \\
\hline \multicolumn{5}{|l|}{ Residence } \\
\hline Urban & $220(78)$ & $62(22)$ & $1.63(1.02,2.61)$ & $1.89(1.11,3.22)$ \\
\hline Rural & $87(68.5)$ & $40(31.5)$ & 1 & 1 \\
\hline \multicolumn{5}{|l|}{ Religion } \\
\hline Christian & $238(74.6)$ & $81(25.4)$ & $0.89(0.52,1.55)$ & \\
\hline Muslim & $69(76.7)$ & $21(23.3)$ & 1 & \\
\hline \multicolumn{5}{|l|}{ Educational status } \\
\hline No formal education & $101(77.1)$ & $30(22.9)$ & $0.98(0.58,1.65)$ & $1.18(0.65,2.13)$ \\
\hline Primary school & $44(63.8)$ & $25(36.2)$ & $0.51(0.28,0.92)$ & $0.49(0.27,0.91)^{*}$ \\
\hline Secondary school (+) & $162(77.5)$ & $47(22.5)$ & 1 & 1 \\
\hline \multicolumn{5}{|l|}{ Occupation } \\
\hline Housewife & $172(74.8)$ & $58(25.2)$ & $0.92(0.55,1.55)$ & \\
\hline Private business & $45(73.8)$ & $16(26.2)$ & $0.88(0.43,1.78)$ & \\
\hline Governmental employed & $90(76.3)$ & $28(23.7)$ & 1 & \\
\hline \multicolumn{5}{|l|}{ Monthly income } \\
\hline$\leq 2500$ & $43(69.4)$ & 19 (30.6) & $0.71(0.39,1.29)$ & \\
\hline$>2500$ & $264(76.1)$ & $83(23.9)$ & 1 & \\
\hline \multicolumn{5}{|l|}{ Number of birth attendants } \\
\hline $1-2$ & $208(75.6)$ & $67(24.4)$ & $1.10(0.68,1.76)$ & \\
\hline$\geq 3$ & $99(73.9)$ & $35(26.1)$ & 1 & \\
\hline \multicolumn{5}{|l|}{ Parity } \\
\hline Primiparous & $93(72.7)$ & $35(27.3)$ & $0.83(0.52,1.34)$ & \\
\hline Multiparous & $214(76.2)$ & $67(23.8)$ & 1 & \\
\hline \multicolumn{5}{|l|}{ Mode of delivery } \\
\hline SVD & $185(76.4)$ & $57(23.6)$ & $1.20(0.76,1.88)$ & \\
\hline $\mathrm{C} / \mathrm{S}$ & $122(73.1)$ & $45(26.9)$ & 1 & \\
\hline \multicolumn{5}{|l|}{ Staying hour } \\
\hline$\leq 24$ & $223(74.1)$ & $78(25.9)$ & $0.82(0.49,1.38)$ & \\
\hline$>24$ & $84(77.8)$ & $24(22.2)$ & 1 & \\
\hline \multicolumn{5}{|c|}{ History of previous facility delivery } \\
\hline No & $137(72.1)$ & $53(27.9)$ & $0.75(0.48,1.17)$ & $0.71(0.44,1.14)$ \\
\hline Yes & $170(77.6)$ & $49(22.4)$ & 1 & 1 \\
\hline \multicolumn{5}{|l|}{ Person attending labor } \\
\hline Midwives & $141(73.1)$ & $52(26.9)$ & $0.77(0.38,1.53)$ & \\
\hline Obstetricians (resident+) & $120(76.4)$ & $37(23.6)$ & $0.92(0.45,1.88)$ & \\
\hline Interns & $46(78)$ & $13(22)$ & 1 & \\
\hline \multicolumn{5}{|l|}{ Time of birth } \\
\hline Day & $199(73.7)$ & $71(26.3)$ & $0.81(0.50,1.30)$ & \\
\hline Night & $108(77.8)$ & $31(22.3)$ & 1 & \\
\hline \multicolumn{5}{|l|}{ Birth attendant's gender } \\
\hline Female & $117(74.1)$ & $41(25.9)$ & $0.92(0.58,1.45)$ & \\
\hline Male & $190(75.7)$ & $61(24.3)$ & 1 & \\
\hline
\end{tabular}


who are not aware of their rights and have never been exposed to any other system of care are not sensitive to the disrespect and abuse of health care workers and see such behavior and attitude as status [5]. Hence, rural resident women are not likely to report being subjected to OV.

This study also shows that there is a significant association between educational status of the respondents and the OV. Accordingly, women who had attended only primary education were $51 \%$ less likely to report any form of OV than those who had attended secondary education and above. This finding is in accordance with previous studies done in Jimma University Medical Center in Southwest Ethiopia [14] and Tigray in Northern Ethiopia [16]. This independent association could convince since educated women are better aware of their rights and thus are more perceptive enough to report all likelihood of being subjected to any form of OV.

\section{Conclusion}

This study demonstrated high prevalence of OV in the study setting and was significantly associated with urban residents and primary school attendants. The top three common reported forms of $\mathrm{OV}$ were non-consented care, non-dignified care and physical abuse. Thus, interventions need to be undertaken by taking the reported forms of obstetric violence and participants' sociodemographic status in to account.

\section{Limitations}

This study was entirely made based on interview rather than observation. In addition, the author recommended further studies to be carried out using a qualitative approach.

\section{Supplementary information}

Supplementary information accompanies this paper at https://doi. org/10.1186/s13104-019-4614-4.

Additional file 1: Annex S1. Sample size determination.

Additional file 2: Annex S2. Verification criteria for the seven performance standards (categories of obstetric violence) which employed to measure obstetric violence [16].

Additional file 3: Figure S1. Forms of obstetric violence reported by participants in Gondar University Comprehensive and Specialized Hospital, Northwest, Ethiopia, 2019.

\section{Abbreviations}

GUCSH: Gondar University Comprehensive Specialized Hospital; OV: obstetric violence.

\section{Acknowledgements}

I would like to acknowledge University of Gondar for providing ethical letter. I am also glade to Gondar University comprehensive specialized hospital medical director's office for writing permission letter. I also like to forward my deepest appreciation to all data collectors and study participants.

\section{Authors' contributions}

MSM: designed the study, performed analysis and interpretation of data and drafted and revised the manuscript. The author read and approved the final manuscript.

\section{Funding}

The research was not supported by any grant.

\section{Availability of data and materials}

The datasets employed in the current study can be available from the corresponding author upon the reasonable request.

\section{Ethics approval and consent to participate}

The ethical clearance was obtained from Institutional Review Board (IRB) of University of Gondar via School of Midwifery, College of Medicine and Health Sciences. An official letter of cooperation was written from Gondar University comprehensive specialized hospital's medical directorate to Maternity ward. Written informed consent of the respondents was then obtained after giving respondents adequate information on the aim of the study, potential risks and benefits of being participant, and the rights of the respondents. At each step, the participants' privacy and confidentiality issues had been assured.

\section{Consent for publication}

Not applicable.

\section{Competing interests}

The author declares that there is no competing interests.

Received: 15 August 2019 Accepted: 6 September 2019

Published online: 18 September 2019

\section{References}

1. Internataional Days of Action for Women's Health. https://www.may28 .org/obstetric-violence/. 2018.

2. Kruk ME, et al. Disrespectful and abusive treatment during facility delivery in Tanzania: a facility and community survey. Health Policy Plan. 2014:33:079.

3. USIAD. Women friendly care guide. 2013.

4. WHO. Health in 2015 from MDGs to SMDGs. Geneva: WHO; 2015.

5. Ishola F, Owolabi O, Filippi V. Disrespect and abuse of women during childbirth in Nigeria: a systematic review. PLoS ONE. 2017;12(3):e0174084.

6. WHO and UNICEF. Trends in maternal mortality: 1990 to 2013: estimates by WHO, UNICEF, UNFPA. The World Bank and the United Nations Population Division: executive summary; 2014.

7. WHO. Ethiopia Demographic and Health Survey. The DHS ProgramICFRockville, Maryland, USA. 2016. p. 39.

8. UNIFECF. SOWC-statistical table; 2017.

9. UN. The 2030 agenda for sustainable development; 2015.

10. Moindi RO, et al. Why mothers still deliver at home: understanding factors associated with home deliveries and cultural practices in rural coastal Kenya, a cross-section study. BMC Public Health. 2016;16:114.

11. DHS. Ethiopian demographic and health survey 2016 key indicators report. Central Statistical Agency; 2016.

12. EFMOH. Basic emergency obstetric \& newborn care (BEmONC); 2018.

13. Gitonga $E$, Muiruri F. Determinants of health facility delivery among women in Tharaka Nithi county. Kenya Pan Afr Med J. 2016;25:9.

14. Siraj A, Teka W, Hebo H. Prevalence of disrespect and abuse during facility based child birth and associated factors, Jimma University Medical Center, Southwest Ethiopia. BMC Pregnancy Childbirth. 2019;19:185.

15. Wassihun B, et al. Prevalence of disrespect and abuse of women during child birth and associated factors in Bahir Dar town, Ethiopia. Epidemiol Health. 2018;40:e2018029.

16. Gebremichael MW, et al. Mothers' experience of disrespect and abuse during maternity care in Northern Ethiopia. Glob Health Action. 2018;11:1465215.

17. Amole TG, et al. Disrespect and abuse during facility based childbirth: the experience of mothers in Kano, Northern Nigeria. Trop J Obstet Gynaecol. 2019;36(1):21-7. 
18. Reis V, et al. Respectful maternity care, 2012. https://www.k4health.org/ sites/default/files/RMC\%20Survey\%20Report_0.pdf. 2012. Accessed 16 July 2018.

19. Asefa A, Bekele D. Status of respectful and non-abusive care during facility-based childbirth in a hospital and health centers in Addis Ababa, Ethiopia. Reprod Health. 2015;12:33.

20. Bobo FT, et al. Disrespect and abuse during childbirth in Western Ethiopia: should women continue to tolerate? PLOS ONE. 2019;14(6):e0217126.

21. Abuya T, et al. Exploring the prevalence of disrespect and abuse during childbirth in Kenya. PLOS ONE. 2015;10(4):e0123606.

22. Mesenburg MA, et al. Disrespect and abuse of women during the process of childbirth in the 2015 Pelotas birth cohort. Reprod Health. 2018;15:54.

23. Bhattacharya S, Ravindran TKS. Silent voices: institutional disrespect and abuse during delivery among women of Varanasi district, northern India. BMC Pregnancy Childbirth. 2018;18:338.

24. Goli S, et al. Labour room violence in Uttar Pradesh, India: evidence from longitudinal study of pregnancy and childbirth. BMJ Open. 2019;9:e028688.

25. Kassa ZY, Husen S. Disrespectful and abusive behavior during childbirth and maternity care in Ethiopia: a systematic review and meta-analysis. BMC Res Notes. 2019;12:83.
26. Banks KP, Karim AM, Ratcliffe HL, Betemariam W, Langer A. Jeopardizing quality at the frontline of healthcare: prevalence and risk factors for disrespect and abuse during facility-based childbirth in Ethiopia. Health Policy Plan. 2018;2018(33):317-27.

27. Sheferaw ED, et al. Respectful maternity care in Ethiopian public health facilities. Reprod Health. 2017;14:60.

28. Sethi $R$, et al. The prevalence of disrespect and abuse during facilitybased maternity care in Malawi: evidence from direct observations of labor and delivery. Reprod Health. 2017;14:111.

29. Ndwiga C, et al. Exploring provider perspectives on respectful maternity care in Kenya: "work with what you have". Reprod Health. 2017;14:99.

30. Wassihun B, Zeleke S. Compassionate and respectful maternity care during facility based child birth and women's intent to use maternity service in Bahir Dar, Ethiopia. BMC Pregnancy Childbirth. 2018;18:294.

\section{Publisher's Note}

Springer Nature remains neutral with regard to jurisdictional claims in published maps and institutional affiliations.
Ready to submit your research? Choose BMC and benefit from:

- fast, convenient online submission

- thorough peer review by experienced researchers in your field

- rapid publication on acceptance

- support for research data, including large and complex data types

- gold Open Access which fosters wider collaboration and increased citations

- maximum visibility for your research: over $100 \mathrm{M}$ website views per year

At BMC, research is always in progress.

Learn more biomedcentral.com/submissions 